\title{
(Des)patologização da vida: perspectiva de assistentes sociais no Recôncavo Baiano'
}

\author{
(De)pathologizing of life: perspectives of social workers in Recôncavo of Bahia
}

Vinicius Pinheiro de MAGALHÃES*

http://orcid.org/oooo-0002-2909-3517

\author{
Vera Núbia SANTOS** \\ http://orcid.org/o0oo-0002-9040-7140
}

Resumo: Este trabalho teve como propósito analisar a concepção de profissionais do Serviço Social sobre a loucura e tratamento de usuários dos Centros de Atenção Psicossocial (CAPS), e a relação entre suas considerações e o Projeto Ético-Político (PEP) profissional. A pesquisa teve natureza empírica e abordagem qualitativa. Foram entrevistados cinco assistentes sociais dos CAPS I de municípios do Recôncavo Baiano, para posterior análise de conteúdo por categorização temática. As considerações dos assistentes sociais foram enquadradas numa perspectiva psicossocial, pois dialogam tanto com pressupostos biologicistas e patologizadores, como com a dimensão da cidadania. O destaque, portanto, é a necessidade de a categoria estabelecer relações mais orgânicas com os movimentos sociais vinculados à Luta Antimanicomial, os quais atuam numa perspectiva essencialmente despatologizadora da vida.

Palavras-chave: Saúde Mental. Serviço Social. Luta Antimanicomial. Despatologização da Vida.

\begin{abstract}
This work was guided by the purpose of analyzing the conception of Social Service professionals about the madness and treatment of users of the Psychosocial Care Centers (Centros de Atenção Psicossocial [CAPS]) and the relationship between their considerations and the professional EthicalPolitical Project (EPP). The research had an empirical nature and a qualitative approach. Interviews were carried out with five social workers of CAPS I from the municipalities of Recôncavo Baiano and content analysis by thematic categorization was used. The considerations of social workers were outlined in a psychosocial perspective, as they dialogue with both biological and pathological assumptions, and with the dimension of citizenship. It is highlighted, therefore, the need for this professional category to establish more organic relations with the social movements linked to the Anti-Asylum Fight, which act in an essentially de-pathologizing perspective of life.
\end{abstract}

Keywords: Mental health. Social Work. Anti-Asylum Fight. De-pathologizing of life.

Submetido em: 25/2/2020. Aceito em: 9/5/2020.

\begin{abstract}
${ }_{1}^{1}$ Artigo resultante de parte dos resultados da dissertação de Mestrado intitulada Serviço Social, (des)patologização da vida e religiosidade em saúde mental, defendida em fevereiro de 2020 no Programa de Pós-graduação em Serviço Social da Universidade Federal de Sergipe (PROSS/UFS) e aprovada com orientação à publicação. $\mathrm{O}$ trabalho foi realizado com apoio da Coordenação de Aperfeiçoamento de Pessoal de Nível Superior - Brasil (CAPES) - Código de Financiamento o01.

* Assistente social. Mestre em Serviço Social pelo Programa de Pós-graduação da Universidade Federal de Sergipe (UFS, São Cristóvão, Brasil). Cidade Universitária José Aloísio de Campos, Rosa Elze, CEP: 49100-00o, São Cristóvão (SE). E-mail: viniciuspmaga@gmail.com.

${ }^{* *}$ Assistente social. Doutora em Serviço Social. Docente efetiva do Departamento de Serviço Social da Universidade Federal de Sergipe (UFS, São Cristóvão, Brasil). Cidade Universitária José Aloísio de Campos, Rosa Elze, CEP: 49100-ooo, São Cristóvão (SE). E-mail: venus_se@uol.com.br.
\end{abstract} copiar e redistribuir o material em qualquer suporte ou formato, bem como adaptar, transformar e criar a partir deste material para qualquer fim, mesmo que comercial. O licenciante não pode revogar estes direitos desde que você respeite os termos da licença. 


\section{Introdução}

crítica empreendida por Foucault (1978) direcionada ao conceito frágil e flexível
de loucura alcançou o saber médico-psiquiátrico e influenciou uma série de
movimentos de negação da psiquiatria.

As características deste saber, que tinha na loucura o seu objeto de atuação, são balizadas numa perspectiva biomédica, num conceito restrito de saúde, num tratamento asilar, numa lógica manicomial, patologizadora da vida e, por conseguinte, legitimadora e fomentadora da Big Pharma².

Contra esta tendência manicomial surgiram os movimentos de Reforma Psiquiátrica e de Luta Antimanicomial centrados numa militância por mudanças na atenção à pessoa com sofrimento mental nas dimensões técnico-assistenciais, político-jurídicas, teóricoconceituais e, sobretudo, socioculturais (AMARANTE, 2007).

Neste trabalho, despatologização da vida, portanto, se associa aos processos de resistência à lógica manicomial de patologização, na medida em que busca superar a noção de loucura como patologia, a fim de concebê-la como processo de sofrimento mental determinada por conjunturas político-econômicas e socioculturais específicas.

Se nos últimos anos foi possível ampliar as redes de atenção psicossocial (RAPS) em todo o Brasil, processo que tem retrocedido na atual conjuntura político-econômica; resta saber se o espírito da Reforma Psiquiátrica tem dirigido os processos de trabalho em Saúde Mental dos profissionais das pretensas instituições substitutas dos hospitais psiquiátricos.

Desse modo, é relevante propor pesquisas que procurem avaliar a pregnância dos ideais da Reforma Psiquiátrica em trabalhadores da Política de Saúde Mental, o que inclui os assistentes sociais.

Este trabalho norteou-se pelo propósito de analisar a concepção de profissionais do Serviço Social, trabalhadores da política de Saúde Mental, sobre a loucura e tratamento de usuários dos Centros de Atenção Psicossocial (CAPS) e a relação entre suas considerações e o Projeto Ético-Político (PEP) profissional.

Tratou-se o objeto de estudo na perspectiva do materialismo histórico-dialético. A pesquisa teve natureza empírica e abordagem qualitativa, com utilização de dados primários, coletados mediante uso do instrumento da entrevista semiestruturada, e secundários, através de revisões da literatura.

Fizeram-se entrevistas com cinco assistentes sociais dos CAPS I de municípios do Recôncavo Baiano. Na interpretação dos dados das entrevistas utilizou-se a análise de conteúdo por categorização temática.

\footnotetext{
${ }^{2}$ Expressão de língua inglesa utilizada para se referir ao complexo industrial farmacêutico.
}

Argum., Vitória, v. 12, n. 2, p. 185-201, maio/ago. 2020. | ISSN 2176-9575 
O projeto do estudo passou por avaliação do Comitê de Ética na Pesquisa da Universidade Federal de Sergipe (UFS) e foi aprovado, de acordo com o Parecer no 3.209.96o; CAAE: 07947819.3.0000.5546.

Desenvolveu-se este trabalho expondo algumas tendências manifestadas pela literatura da Saúde Mental acerca de perspectivas de loucura e tratamento e sua relação com a (des)patologização da vida3 . Em seguida, procurou-se enquadrar a concepção de loucura e tratamento dos assistentes sociais entrevistados, propondo uma análise crítica de suas representações.

\section{Perspectivas de loucura e tratamento no contexto da (des)patologização da vida}

As concepções (des)patologizadoras da vida, em nosso ponto de vista, forjado com base na avaliação crítica da literatura do campo da Saúde Mental, são constituídas de três perspectivas distintas referentes à loucura e seu tratamento, a saber: a perspectiva manicomial, a perspectiva psicossocial e a perspectiva antimanicomial4.

A perspectiva manicomial sobre as concepções de loucura e tratamento é baseada na ótica do alienismo pineliano, pensamento germinador da psiquiatria moderna.

O alienismo pineliano, contraditoriamente engendrado no bojo de experiências revolucionárias francesas, é constituído de três pontos essenciais: a) o conceito de alienação mental; b) o isolamento do mundo exterior; e c) o tratamento moral.

Apesar de o conceito de alienação mental em Philippe Pinel (1745-1826) não tratar a loucura como uma doença, sua teoria a concebe como uma desordem da mente que impossibilita a percepção da realidade (AMARANTE, 2007).

Para Amarante (2007), é justamente esse conceito de alienação mental que influencia a associação da loucura à periculosidade, concepção ressonante até hoje, que se torna uma concepção legitimadora de abordagens médicas policialescas e persecutórias.

Outra abordagem do alienismo pineliano é a proposta de isolamento do mundo exterior como elemento terapêutico. Esse primeiro passo para o tratamento - o isolamento -

3 Utilizou-se o termo (des)patologização com o prefixo des entre parênteses para destacar que o contexto das considerações de assistentes sociais sobre loucura e tratamento é flexível, uma vez que pode ser constituído de uma concepção patologizadora ou despatologizadora da vida. Nesse sentido, quando o termo apresentar-se escrito sem os parênteses (patologização ou despatologização) significa que o objetivo argumentativo é destacar a especificidade de determinada dimensão do conceito e não sua flexibilidade.

4 Trata-se de uma hipótese dos autores que ainda precisa ser aprofundada, mas que tem sido sinalizada de forma implícita em Amarante (1997, 2007), Freitas e Amarante (2015), Amarante, Pitta e Oliveira (2018) e, sobretudo, em Luzio e Yasui (2010) - para estes teóricos a mudança do paradigma de atenção à pessoa com sofrimento mental não deve se restringir à construção de instituições psicossociais e extrahospitalares, mas envolver uma transformação sociocultural balizada no ideal antimanicomial de despatologização da vida, o que, em nosso ponto de vista, sugere a hibridez (despatologizadora com resquícios de patologização) de uma perspectiva progressista (psicossocial) sobre a loucura e tratamento. Torna-se necessário, portanto, diferenciar a perspectiva psicossocial da antimanicomial, esta sim essencialmente despatologizadora da vida. 
permitia um afastamento de interferências exteriores, determinantes da alienação, a fim de viabilizar dedicação integral a certo tipo de tratamento moral.

O tratamento moral, por sua vez, configurava-se numa proposta de reeducação do louco, mediante cumprimento de princípios e incorporação de valores. Tratava-se de verdadeiros processos de adequação às normas (morais) das instituições psiquiátricas. A proposta terapêutica de Pinel era a de dar centralidade no tratamento da doença a despeito do sujeito portador da doença. Surgia a abordagem hospitalocêntrica que caracterizou os manicômios modernos.

A perspectiva do alienismo pineliano foi o germe para a constituição da psiquiatria moderna. Logo, essa tendência de tratamento do louco, mais centrada nas questões da segurança e periculosidade, estender-se-ia mundo afora nos meandros do saber psiquiátrico.

A perspectiva manicomial, portanto, intrinsecamente relacionada ao alienismo pineliano moderno (a psiquiatria), circunscreve-se numa concepção patologizadora da vida.

A alienação, que posteriormente se tornou doença, é superdimensionada em detrimento do sujeito que vive a experiência da loucura; o louco é um caso de segurança pública; o isolamento e a reforma moral são terapêuticas essenciais (AMARANTE, 2007); o controle da loucura, de corpos desviantes, via medicamentalização e isolamento, é fomentado (MOYSÉS; COLLARES, 2018); o setor privado da loucura e a indústria farmacêutica são estimulados (AMARANTE, 1997; OLIVEIRA, 2018) e novos neurolépticos são criados, sustentados em duvidosas comprovações científicas e comercializados mediante autorização de um Estado cooptado pela força econômica da Big Pharma (WHITAKER, 2017).

Noutra direção, Paulo Amarante (1995; 2007) apresenta algumas características das experiências que protagonizaram a crítica ao alienismo pineliano e influenciaram a perspectiva psicossocial.

Foi no contexto do pós-Segunda Guerra que surgiram as primeiras experiências de reformas psiquiátricas, num quadro de crise do capitalismo e de catalisação dos direitos humanos.

Amarante (2007) divide essas experiências em três grupos, ou como o autor prefere, em “[...] dois grupos mais um [...]" (AMARANTE, 2007, p. 41): 1o grupo - Comunidades Terapêuticas e Psicoterapia Institucional; $2^{\circ}$ grupo - Psiquiatria de Setor ou Comunitária e Psiquiatria Preventiva; e $3^{\underline{0}}$ grupo (mais um) - Antipsiquiatria e Psiquiatria Democrática.

Com relação ao primeiro grupo, Amarante (2007, p. 41) afirma que se tratou de uma experiência que lançou seus esforços na tentativa de recuperação da instituição, uma vez que se baseou na compreensão de que “[...] o fracasso [das instituições psiquiátricas] 
estava na forma de gestão do próprio hospital e que a solução, portanto, seria introduzir mudanças na instituição" (AMARANTE, 2007, p. 41).

As experiências de reforma psiquiátrica do segundo grupo, representado pela Psiquiatria de Setor e pela Psiquiatria Preventiva, ampararam-se na crença de que

[...] o modelo hospitalar estava esgotado, e que o mesmo deveria ser desmontado "pelas beiradas" [...] isto é, deveria ser tornado obsoleto a partir da construção de serviços assistenciais que iriam qualificando o trabalho terapêutico. (AMARANTE, 2007, p. 41).

Aduz-se do pensamento transcrito acima que se tratava de uma reforma lenta, a qual almejava, em última instância, tornar o hospital psiquiátrico desnecessário mediante construção de serviços e instituições extra-hospitalares.

Os experimentos do terceiro e último grupo, ao contrário dos anteriores, não tiveram características reformistas. As experiências da Antipsiquiatria e da Psiquiatria Democrática, nos termos de Amarante (2007, p. 41), “[...] [consideraram] que a questão mesma estaria no modelo científico psiquiátrico, que é todo ele colocado em xeque, assim como suas instituições assistenciais" (AMARANTE, 2007, p. 41). Esse grupo germinou experiências de ruptura com o modelo psiquiátrico e foi o que mais influenciou a reforma psiquiátrica brasileira.

O legado das experiências reformistas de atenção psiquiátrica e críticas da vertente do alienismo pineliano pode ser resumido mediante a exposição das seguintes características da perspectiva de atenção psicossocial: valorização da humanização hospitalar; horizontalização das relações institucionais; valorização de abordagens trans/interdisciplinares; valorização de instituições extra-hospitalares; inflexão no eixo de atenção da doença para a pessoa com sofrimento mental; ruptura com práticas terapêuticas de isolamento e valorização de estratégias de promoção da cidadania como elemento terapêutico.

Apesar da tentativa de rompimento com o modelo de assistência psiquiátrica manicomial, com o advento da reforma psiquiátrica brasileira algumas abordagens patologizadoras ainda persistem, mesmo em serviços de atenção psicossocial.

Exemplo disso é o superdimensionamento do saber médico-psiquiátrico em instituições como os CAPS e a supervalorização do tratamento medicamentoso a despeito da RAPS, da multiprofissionalidade e da diversidade das dimensões de tratamento (JORGE; BEZERRA, 2018). Por esse motivo, considera-se, neste trabalho, a tendência psicossocial como uma perspectiva híbrida, uma vez que dialoga com a despatologização e também com a patologização da vida.

Na perspectiva antimanicomial, tendência influenciada pelo II Congresso Nacional de Trabalhadores em Saúde Mental (1987), também conhecido como Encontro de Bauru, o qual sintetizou o compromisso dos atores que compuseram o Movimento de Trabalhadores da Saúde Mental (MTSM) de romper com o modelo manicomial, via organização popular e sindical, para superação da sociedade produtora de sofrimento 
mental, a loucura é considerada uma produção extrínseca de relações sociais injustas, de exploração e de desigualdade (CONGRESSO NACIONAL DE TRABALHADORES EM SAÚDE MENTAL, 1987). A terapêutica, nesse sentido, envolveria a reversão do quadro macrossocietário produtor da loucura.

Apesar das semelhanças com a perspectiva psicossocial, sobretudo no que se refere à concepção da loucura como produto extrínseco das relações sociais, a perspectiva antimanicomial é essencialmente despatologizadora da vida, uma vez que concebe a experiência da loucura não como uma doença, mas como um sofrimento mental determinado em conjunturas político-econômico-sociais específicas.

Infere-se, mediante a exposição da hipótese acerca da existência dessas três perspectivas como tendências no campo da saúde mental - especialmente das perspectivas psicossocial e antimanicomial -, que a Reforma Psiquiátrica brasileira não necessariamente foi ineficaz, mas incompleta, uma vez que, além dos desafios futuros de aumentar o número das instituições substitutas dos hospitais psiquiátricos, ainda precisa vislumbrar a generalização de um ideário despatologizador da vida e antimanicomial, utopia ainda muito distante de inúmeros profissionais de instituições psicossociais e extra-hospitalares, os quais reproduzem um saber híbrido sobre a loucura num quadro de recrudescimento de políticas neoliberais de legitimação de hospitais psiquiátricos e da indústria farmacêutica.

\section{Análise e discussão dos dados coletados nas entrevistas}

O processo de análise dos relatos dos entrevistados decorre das seguintes perguntas do roteiro de entrevista: a) Quem é o usuário do CAPS? (perfil, história e trajetória); b) de que forma se dá o tratamento da pessoa em tratamento no CAPS? (necessidades de saúde, rotina na instituição); c) o que cabe ao Serviço Social no CAPS? e d) de que forma seu trabalho no CAPS dialoga com o Projeto Ético-político da profissão (PEP)?

A análise das entrevistas permitiu chegar a duas categorias finais sobre as considerações de loucura e tratamento, a saber: a) Loucura associada a um diagnóstico determinado extrinsecamente; e b) tratamento psicossocial com ênfase no campo psi, o qual incorpora a dimensão da cidadania restrita como elemento terapêutico complementar.

A seguir expõem-se as unidades de sentido que constituem essas categorias, bem como as mediações históricas e conceituais que envolvem os elementos manifestos na análise de conteúdo.

\subsection{Loucura como um determinante extrínseco}

A pergunta cujo objetivo foi perquirir os assistentes sociais sobre o perfil dos usuários do CAPS revelou-se a que melhor permitiu uma aproximação da concepção de loucura dos entrevistados. Todos os entrevistados relacionaram a condição de loucura a uma dimensão extrínseca.

Argum., Vitória, v. 12, n. 2, p. 185-201, maio/ago. 2020. | ISSN 2176-9575 
O Entrevistado 1 associou o usuário do CAPS à obstrução de direitos “[...] São pessoas, geralmente, [...] sem benefícios, tanto sem benefício financeiro, quanto benefícios sociais $[\ldots] "$.

Além desse, outros determinantes extrínsecos também foram destacados pelo entrevistado, a exemplo dos conflitos familiares: “[...] são pessoas fragilizadas nesse aspecto, fragilizadas em relação aos seus vínculos familiares [...]”. De forma semelhante, para o Entrevistado 3 "São pessoas que [...] muitas das vezes [vivem situações] baseadas em conflitos familiares”.

Ademais, a loucura também esteve associada a desapontamentos, sofrimentos profundos e a experiências religiosas danosas.

A perspectiva manicomial do alienismo pineliano, da mesma forma, ancorou-se na premissa de que a alienação era produzida numa dimensão extrínseca, o que legitimou o isolamento de influências danosas externas como forma de tratamento (AMARANTE, 2007).

O legado das experiências reformistas que constituíram o caldo no qual se baseou a perspectiva psicossocial, sobretudo ancorado no grupo da Antipsiquiatria e da Psiquiatria Democrática, também dá ênfase à produção extrínseca da loucura, mas com uma proposta terapêutica diferente da de Pinel.

O remédio seria uma ruptura com a psiquiatria, a fim de entender as relações extrínsecas, externas, sociais que produziam a experiência da loucura e, a partir dessa compreensão, desenvolver uma terapêutica relacionada a processos de reversão das relações sociais produtoras de sofrimento mental (AMARANTE, 1997, 2007).

Resta saber a forma como a Psiquiatria moderna lidou com a experiência da loucura, empreendimento que contextualiza a discussão do próximo núcleo de sentido.

\subsection{Loucura como um diagnóstico}

Outro núcleo de sentido que surgiu da análise de conteúdo da maioria dos entrevistados foi a associação da loucura a um diagnóstico.

Sobre os usuários do CAPS, os entrevistados afirmaram: “[...] pessoas com transtornos mentais graves e persistentes" (Entrevistado 2); “[Pessoas que possuem] Transtornos graves e persistentes [como a] bipolaridade, a esquizofrenia, a ansiedade [...], epilepsia, junto com outros tipos de transtornos" (Entrevistado 3); “[...] depressivos, [pessoas que têm] distúrbio mental [...]" (Entrevistado 4); "[...] pessoa que se sente com a Saúde Mental comprometida, seja por transtorno de ansiedade, depressão, seja por alguma coisa congênita [...], esquizofrenia, uma pessoa que tem transtorno mental [...]" (Entrevistado 5).

É necessário fazer uma breve contextualização histórica para que se compreenda a pregnância da perspectiva diagnóstica no contexto da Saúde Mental. 
Robert Whitaker (2017), Fernando Freitas e Paulo Amarante (2015), ao tratarem sobre o processo de constituição da psiquiatria hodierna, mencionam certa revolução farmacológica que emergiu no século XX.

No momento em que o saber médico avançava com o desenvolvimento de remédios para diversas doenças, a especialidade da psiquiatria ainda se expressava nos meandros bárbaros do manicômio pineliano para o tratamento da loucura.

Com o desencadeamento do movimento de humanização nos hospitais psiquiátricos, no mesmo contexto norte-americano de avanço biotecnológico, "[...] foi fácil para todos ter uma visão de onde se poderia encontrar uma solução de longo prazo [para a preocupação com a loucura]. O país poderia depositar sua confiança nos poderes transformadores da ciência" (WHITAKER, 2017, p. 6o).

A loucura tornou-se uma doença mental, conceito derivado do saber psiquiátrico moderno, ancorado, sobretudo, numa perspectiva biologicista5 influenciada pelos avanços científicos do combate às doenças infecciosas.

Três agentes foram fundamentais para o desenvolvimento do novo projeto da Psiquiatria de combate farmacológico da loucura: os médicos, a indústria farmacêutica e o Estado (FREITAS; AMARANTE, 2015).

Os médicos-pesquisadores desenvolviam pesquisas que legitimavam a perspectiva biologicista da Psiquiatria; o Estado, além de dar fomento à pesquisa, aprovava os novos medicamentos e à indústria farmacêutica cabia a comercialização (FREITAS; AMARANTE, 2015; WHITAKER, 2017).

O elemento fundamental dessa comunhão lucrativa foi o da tese da loucura como um desequilíbrio químico do cérebro ${ }^{6}$ (FREITAS; AMARANTE, 2015, WHITAKER, 2017), ou seja, a loucura determinada por uma dimensão intrínseca - perspectiva contrária à expressa pelos participantes da pesquisa:

Esta ideia está baseada na teoria de que enfermidades mentais são resultado de desequilíbrio químico do cérebro e, consequentemente, faz com que a terapêutica seja vista como a forma de possibilitar o reajuste do equilíbrio químico, o que de fato acontece apenas por meio de prescrição de antipsicóticos, antidepressivos e ansiolíticos (FREITAS; AMARANTE, 2015, p. 77-78).

Trata-se de uma teoria que simplifica a complexidade cerebral e o fenômeno da loucura, relacionando-os a meros intercâmbios químicos. A Psiquiatria moderna não consentiu em comungar com esta sensação de ignorância diante do incomensurável - a ideia, a mente, a loucura - e se deteve na mais rasa das explicações para as desordens mentais: desequilíbrio da serotonina, dopamina e noradrelina nas sinapses cerebrais, teoria

5 Saber médico centrado na dimensão biológica em detrimento das dimensões psicológicas, sociais e culturais.

6 "A hipótese do desequilíbrio químico está relacionada com quantidades alteradas de serotonina, noradrenalina e/ou dopamina nas sinapses do cérebro" (FREITAS; AMARANTE, 2015, p. 80).

Argum., Vitória, v. 12, n. 2, p. 185-201, maio/ago. 2020. | ISSN 2176-9575 
contraposta pelos estudos de Malcolm Bowers, Joseph Mendels e Alan Frazer, James Maas, David Burns e David Healy (WHITAKER, 2017).

A psiquiatria, portanto, legitimou o tratamento da loucura com pílulas mágicas, na medida em que compreendeu tratar-se de antídotos contra o desequilíbrio químico do cérebro; teoria proposta pelos doutores Joseph Schildkraut e Jacques Van Rossum na década de 196o (WHITAKER, 2017).

A loucura transitou do conceito de alienação para a versão contemporânea do conceito de doença, o transtorno mental (FREITAS; AMARANTE, 2015).

A construção social da noção de doença, processo de preparação do cenário para a emergência da teoria do desequilíbrio químico do cérebro e para a ideia de transtorno mental, precisou de um instrumento de ancoragem diagnóstica, papel assumido pelos diversos manuais diagnósticos e estatísticos de transtornos mentais (DSMs) (FREITAS; AMARANTE, 2015). Esses manuais são instrumentos flexíveis e baseados em critérios diagnósticos imprecisos, de acordo com indicação de Freitas e Amarante (2015).

Nas décadas de 1960/70 a Antipsiquiatria empreendeu diversas críticas a esses critérios de diagnósticos imprecisos. Foi a partir desse contexto que surgiram respostas da Associação Norte-Americana de Psiquiatria (APA), as quais objetivavam a atacar aquele movimento com a publicação dos DSM III, DSM III-R, DSM-IV, DSM-IV-TR e DSM-V7; manuais diagnósticos exaltados pela psiquiatria por sua capacidade avaliativa precisa (FREITAS; AMARANTE, 2015; WHITAKER, 2017).

A respeito do DSM mais recente (DSM-V), Jorge e Bezerra (2018) declaram: “[...] repete o modelo das versões anteriores, apresentando grandes fragilidades epistemológicas e uma lista de sintomas pouco claros para um conjunto cada vez maior de patologias mentais" (JORGE; BEZERRA, 2018, p. 59).

Não obstante os problemas de diagnósticos e a profunda flexibilidade dos DSM, como mostraram as diversas reformulações catalisadas por conflito de interesses (FREITAS; AMARANTE, 2015), esses são os instrumentos exportados para o mundo, a fim de servirem de auxílio ao processo de diagnóstico da loucura em diversas instituições, inclusive psicossociais (JORGE; BEZERRA, 2018).

Se, por um lado, a concepção de loucura adotada por assistentes sociais é de natureza psicossocial e despatologizadora, pelo que reconhece o determinante extrínseco da loucura, por outra vertente é patologizadora, pois legitima abordagens diagnósticas balizadas por um saber biomédico questionável do ponto de vista científico.

\subsection{Tratamento psicossocial com ênfase no campo Psi}

A concepção diagnóstica do fenômeno da loucura, expressa pela maioria dos participantes da pesquisa, caminha na direção de legitimar uma abordagem que tem se

\footnotetext{
7 Manual Diagnóstico mais atual, publicado no ano de 2013.
} 
revelado tendência no contexto das instituições psicossociais: a centralidade do tratamento no campo Psi (JORGE; BEZERRA, 2018).

A loucura, portanto, é um transtorno mental que deve ser tratada, centralmente, no campo biopsicológico.

Na perspectiva dos entrevistados, o tratamento é substancialmente centrado no campo Psi, pois depende: do diagnóstico psiquiátrico (Entrevistado 2); da prescrição medicamentosa fornecida pelo médico psiquiatra (Entrevistado 3 ); e das terapias que se fundem ao tratamento medicamentoso (Entrevistados 3 e 4).

Apesar de mencionarem as oficinas no contexto de tratamento dos usuários, percebe-se uma ênfase no elemento terapêutico centrado no acompanhamento com o médico psiquiatra e com o psicólogo (Entrevistados 1 e 4). Até a alta do serviço do CAPS condiciona-se à análise do psiquiatra (Entrevistado 3 ).

Resta aos assistentes sociais, que, nessa perspectiva, não participam diretamente da dimensão de tratamento do usuário, uma vez que a cidadania não é considerada uma dimensão terapêutica essencial, fazer encaminhamentos aos profissionais do campo Psi (Entrevistados 4 e 5).

A subsunção do Serviço Social ao Saber Psi está relacionada ao que Vasconcelos (2010) chamou de recalque da subjetividade - realidades do inconsciente, personalidade e emoções - o que, para o autor em questão, decorre de uma limitação da perspectiva teórico-metodológica do marxismo ortodoxo, hegemônica no Serviço Social brasileiro, e sinaliza necessidades de diálogos interdisciplinares, interteóricos e interparadigmáticos a serem realizados pela profissão (MAGALHÃES, 2020).

A rejeição das temáticas associadas à subjetividade no Serviço Social pós-reconceituação contribuiu para um empobrecimento da atividade profissional no campo da saúde mental, relegando os assistentes sociais ao lugar de uma atuação técnica de apoio ${ }^{8}$.

Ademais, trata-se de uma subordinação que também se explica por uma relação de saber-poder. A este respeito Augusto Bisneto (2007) afirma:

Nas instituições psiquiátricas o assistente social desenvolve as suas práticas de forma subordinada ao saber médico psiquiátrico, que é o saber com mandato social, isto é, o reconhecimento no plano legal sobre o campo da Saúde Mental, nas condições econômicas, políticas e ideológicas da sociedade burguesa (AUGUSTO BISNETO, 2007, p. 146).

Além do aspecto subordinado do trabalho do assistente social no contexto de hegemonia do saber psiquiátrico, Augusto Bisneto (2007) chama a atenção para o risco de o exercício profissional do Serviço Social tornar-se uma atividade de apoio organizacional:

\footnotetext{
${ }^{8}$ Certamente, trata-se de um fenômeno que possui outros determinantes, a exemplo da imagem social do Serviço Social análoga à condição da mulher na sociedade patriarcal; segmento hegemônico no quadro profissional.
} 
Nas condições da psiquiatria tradicional, às vezes puramente medicamentosa, o assistente social corre o risco de ser relegado disfarçadamente a um agente meramente organizacional, sendo incumbido de tarefas administrativas, tais como conferir a documentação do paciente para constatar seus direitos ao atendimento conveniado, verificar as suas possibilidades de retorno ao lar no tempo hábil de alta, ou mobilizar a família apenas por recursos que ajudem a organização (AUGUSTO BISNETO, 2007, p. 147-148).

Ora, a concepção de cidadania restrita como uma dimensão complementar do tratamento é decorrente da suprarreferida subordinação do saber do Serviço Social ao Saber Psi.

A dimensão da cidadania não ocupa espaço central no processo de tratamento, como defendeu o grupo que rompeu com a psiquiatria, antes assume contornos restritos, subsumidos à lógica do campo Psi.

Pensar num tratamento que tenha a cidadania como elemento central é pensar, prioritariamente, na reversão de relações sociais objetivas determinadas por um quadro macrossocietário.

\subsection{Cidadania restrita como elemento terapêutico complementar}

Os entrevistados afirmaram que suas atividades seguem a tendência de viabilizar acesso às políticas sociais, aos direitos sociais e de possibilitar a inclusão social dos usuários do CAPS, mesma resposta que deram ao destacar as possibilidades dialógicas de seu trabalho com o PEP da profissão:

[...] orientação para [recebimento dos] benefícios [...]. A gente tenta orientar, encaminhar para a secretaria de assistência social, juntamente com o relatório médico, para que eles possam ter acesso a esse benefício (Entrevistado 2).

Trabalho essa questão social. Eu trabalho a questão dos direitos. [...] tem a parte do vínculo com a rede. Quando eu falo vínculo de rede é o vínculo com os PSF, as unidades de saúde. (Entrevistado 3 ).

A questão do benefício que é muito visado aqui no município, eles têm um interesse muito grande. Às vezes não cuida do paciente, mas tem interesse no benefício. Então o Serviço Social vai em busca desse familiar para saber quem está usando esse dinheiro, para saber se realmente está cuidando (Entrevistado 4).

[...] encaminhamento de precariedade habitacional, orientação do benefício, [...] os encaminhamentos, enfim. [...] (Entrevistado 5).

Trata-se de uma concepção ancorada num conceito restrito de cidadania, ou seja, uma concepção de cidadania associada ao direito positivo, consolidado na esfera legal e constitucional.

Concordamos com Coutinho (1999), quando ele afirma as dimensões do direito e da cidadania como elementos anteriores à positivação legal, uma vez que os direitos e a 
cidadania são construções histórico-sociais e não naturais - como quiseram Locke e os jusnaturalistas.

Segundo Coutinho (1999) existe uma incompatibilidade entre a plena universalização da cidadania e a ordem societária do capital:

[...] a divisão da sociedade em classes constitui limite intransponível à afirmação conseqüente da democracia. Como parece óbvio, a condição de classe cria, por um lado, privilégios, e, por outro, déficits, uns e outros aparecendo como óbices a que todos possam participar igualitariamente na apropriação das riquezas espirituais e materiais socialmente criadas (COUTINHO, 1999, p. 57).

Portanto, ainda que formalmente os direitos de cidadania estejam positivados, presentes em legislações e normatizações, sua plena materialização na ordem do capitalismo torna-se inviável. Nesse sentido argumentativo, referem-se a direitos universais, dadas às suas características de total capilaridade, mas que se configuram como abstratos, pois na materialidade da vida real são profundamente negligenciados na dimensão de sua efetivação.

A esta concepção restrita de cidadania - relacionada à positivação de direitos contrapõe-se uma concepção ampliada. Cidadania ampliada, para Coutinho (1999), seria:

[...] a capacidade conquistada por alguns indivíduos, ou (no caso de uma democracia efetiva) por todos os indivíduos, de se apropriarem dos bens socialmente criados, de atualizarem todas as potencialidades de realização humana abertas pela vida social em cada contexto historicamente determinado (COUTINHO, 1999, p. 42).

A cidadania como apropriação coletiva de bens socialmente criados e a atualização de todas as potencialidades de realização humana pressupõem uma efetiva democracia, isto é, "[...] a construção coletiva do espaço público, como a plena participação consciente de todos na gestação e no controle da esfera política” (COUTINHO, 1999, p. 42).

Cidadania ampliada, nesse sentido, encontra-se numa instância superior à emancipação política, conforme debate empreendido por Marx (2010). Trata-se de uma forma de cidadania que se associa à emancipação humana e, por isto mesmo, pressupõe a ruptura com a base material que sustenta o modelo de organização social vigente.

O debate sobre os direitos humanos, sobretudo no bojo do Serviço Social pósreconceituação, configura-se como uma instância mais abrangente do que aquela restrita ao direito positivo, arregimentado pela legislação.

A “[...] defesa intransigente dos direitos humanos [...]" (BRASIL, 2012, p. 23), dever legatário do PEP profissional, decorre da compreensão dos direitos humanos como "[...] um campo epistemológico e de luta social estratégica, no horizonte de construção de uma ordem social libertária, no contexto de um campo de disputa de projetos societários" (VINAGRE, 2011, p. 108); por conseguinte "[...] a concepção de Direitos 
Humanos presente no código de 1993 vai além dos direitos concebidos na sociedade capitalista, pressupõe o horizonte de outra forma de sociabilidade" (MAIOR et al., 2018, p. 134).

Portanto, pensar a cidadania ampliada nos contornos da sociabilidade burguesa é, necessariamente, pensar na organização, disputa e luta políticas na esfera macrossocietária.

Ao contrário da cidadania restrita, aquela subsumida ao direito positivo, a disputa pela cidadania ampliada demanda mobilização ativa, pois é fruto de processos históricosociais determinados por conflitos e luta de classes.

Augusto Bisneto (2013) afirma que no cenário do neoliberalismo as políticas sociais têm sido insistentemente desfinanciadas, tendência que tem descaracterizado o trabalho do assistente social na saúde mental, redirecionando-o, para além das atividades de apoio administrativo (AUGUSTO BISNETO, 2007), a ações afetivas e de lazer.

Se, de um lado, os assistentes sociais entrevistados não vislumbram possibilidades de um exercício profissional mediado por uma concepção ampliada de cidadania concepção convergente com o espírito do PEP profissional -, de outra forma exercem suas atividades num contexto político e social de retração dos direitos sociais e de desfinanciamento das políticas sociais públicas, o que, inexoravelmente, reverbera no sucateamento da política de saúde mental e na descaracterização da atividade profissional.

Esse cenário complexo demanda dos profissionais de Serviço Social uma competência crítica que não sucumba a fatalismos e conformismos, nem a messianismos utopistas (IAMAMOTO, 2009, 2015).

A reflexão filosófico-ontológica da liberdade como valor ético central do atual código de ética e também do PEP profissional caminha justamente na direção de afirmar a capacidade do ser social de fazer escolhas, o que, em última instância, afirma a possibilidade concreta de construção de outra sociabilidade em condições objetivas adversas (BARROCO, 2010; BONETTI, 1998; IAMAMOTO, 2015).

Portanto, uma competência profissional crítica no quadro da saúde mental lança mão da cidadania ampliada, dos direitos humanos ainda não positivados e do espírito do PEP profissional a fim de dar conta das demandas reais da população usuária dos CAPS. Essa ampliação de horizonte colocará a dimensão do tratamento do louco num enfoque macrossocietário, as terapêuticas estarão centradas e condicionadas aos processos de reversão das relações sociais e históricas de produção do sofrimento mental.

Malgrado as condições objetivas adversas para a materialização do PEP profissional no trabalho do assistente social na saúde mental, é possível viabilizar a participação social de usuários, familiares e movimentos sociais no processo de controle social, avaliação e fiscalização dos serviços do CAPS, bem como fornecer as informações necessárias a fim 
de que se medeie a questão da loucura a um quadro macrossocietário, no qual somente forças sociais e políticas organizadas têm poder de influência e intervenção.

Mais uma vez, a concepção dos entrevistados expressou-se de forma complexa. Se de um lado os assistentes sociais dialogaram com a dimensão da cidadania, de outro superdimensionaram o Saber Psi no contexto do tratamento ao restringirem a dimensão terapêutica da cidadania a um lugar de complementariedade.

\section{Considerações finais}

Os assistentes sociais entrevistados demonstraram possuir uma concepção de loucura e tratamento tanto despatologizadora, posto que dialógica com a cidadania e os elementos extrínsecos de produção de sofrimento mental, quanto patologizadora da vida, uma vez que signatária de abordagens biologicistas para caracterizar o público dos CAPSs e cúmplice da tendência de superdimensionamento do Saber Psi.

Portanto, classificou-se a concepção de loucura e tratamento dos assistentes sociais entrevistados na perspectiva psicossocial - vertente híbrida de atenção à loucura localizada no limbo entre a despatologização e a patologização da vida.

Essa concepção dos assistentes sociais reflete um problema da política de Saúde Mental no Brasil após a reforma psiquiátrica. Apesar de ser uma política de atenção psicossocial influenciada por experiências críticas e progressistas, ainda é possível notar a presença de práticas profissionais patologizadoras em espaços institucionais psicossociais (JORGE; BEZERRA, 2018) e reminiscências de um saber biologicista na própria composição da política de Saúde Mental, o que pode ser explicado como uma síntese dos embates entre os atores que disputam o direcionamento da política de saúde no Brasil.

Destaca-se, portanto, a necessidade de a categoria profissional estabelecer relações mais orgânicas com os movimentos sociais vinculados à Luta Antimanicomial, os quais atuam numa perspectiva essencialmente despatologizadora da vida, o que viabiliza possibilidades substantivas de diálogo e convergência com o PEP profissional.

Este intercurso e aproximação podem ser vislumbrados ao passo em que se produzirem mais pesquisas sobre a natureza dos processos de trabalho dos assistentes sociais na lógica da desinstitucionalização psiquiátrica, isto é, da desconstrução da lógica manicomial na dimensão da despatologização da vida.

\section{Referências}

AMARANTE, Paulo. Saúde mental e atenção psicossocial. 3. ed. Rio de Janeiro: Fiocruz, 2007.

AMARANTE, Paulo. Loucura, cultura e subjetividade. Conceitos e estratégias, percursos e atores da reforma psiquiátrica brasileira. In: FLEURY, Sonia (org.). Saúde e democracia: a luta do CEBES. São Paulo: Lemos Editorial, 1997. p. 163-186. 
AMARANTE, Paulo. Loucos pela vida: a trajetória da reforma psiquiátrica no Brasil. 2 ed. Rio de Janeiro: Fiocruz, 1995.

AMARANTE, Paulo; PITTA, Ana Maria Fernandes; OLIVEIRA, Walter Ferreira de (orgs.). Patologização e medicalização da vida: epistemologia e política. São Paulo: Zagodoni, 2018.

AUGUSTO BISNETO, José. Serviço social e atuação na reforma psiquiátrica. In: NICACIO, Erimaldo Matias; BISNETO, José Augusto (orgs.). A prática do assistente social na saúde mental. Rio de Janeiro: Editora UFRJ, 2013· p. 167-188.

AUGUSTO BISNETO, José. Serviço social e saúde mental: uma análise institucional da prática. 3. ed. São Paulo: Cortez, 2007.

BARROCO, Maria Lúcia Silva. Ética: fundamentos sócio-históricos. Biblioteca Básica de Serviço Social. v. 4. 3. ed. São Paulo: Cortez, 2010.

BONETTI, Dilséa Adeodata et al. (orgs.). Serviço Social e ética: convite a uma nova práxis. 2. ed. São Paulo: Cortez, 1998.

BRASIL. Lei 8.662 de o7 de junho de 1993. Dispõe sobre a profissão de Assistente Social e dá outras providências. In: Código de ética do/a assistente social. 10. ed. Brasília: Conselho Federal de Serviço Social (CFESS). Brasília (DF), 2012. Disponível em: http://cfess.org.br/arquivos/CEP_CFESS-SITE.pdf. Acesso em: 20 ago. 2019.

CONGRESSO NACIONAL DE TRABALHADORES EM SAÚDE MENTAL II. Manifesto de Bauru. Anais eletrônicos [...]. Bauru (SP), dez. 1987. Disponível em: https://site.cfp.org.br/wp-content/uploads/2017/o5/manifesto-de-bauru.pdf. Acesso em: 23 dez. 2018.

COUTINHO, Carlos Nelson. Cidadania e modernidade. Perspectiva, Revista de Ciências Sociais, São Paulo: Universidade Estadual Paulista, v. 22, p. 41-59, 1999.

FOUCAULT, Michel. História da loucura na idade clássica. Tradução: José Teixeira Coelho Netto. São Paulo: Perspectiva, 1978.

FREITAS, Fernando; AMARANTE, Paulo. Medicalização em Psiquiatria. Rio de Janeiro: Editora Fiocruz, 2015.

IAMAMOTO, Marilda Villela. O Serviço Social na contemporaneidade: trabalho e formação profissional. 26. ed. São Paulo: Cortez, 2015.

IAMAMOTO, Marilda Villela. O Serviço Social na cena contemporânea. In: CFESS/ABEPSS. Serviço Social: direitos sociais e competências profissionais. Brasília: CFESS/ABEPSS, 2009, p. 15-50. 
JORGE, Maria Salete Bessa; BEZERRA, Indara Cavalcante. A medicalização social e suas repercussões nos serviços de Saúde Mental. In: AMARANTE, Paulo; PITTA, Ana Maria Fernandes; OLIVEIRA, Walter Ferreira de (orgs.). Patologização e medicalização da vida: epistemologia e política. São Paulo: Zagodoni, 2018. p. 57-64.

LUZIO, Cristina Amélia; YASUI, Silvio. Além das portarias: desafios da política de Saúde Mental. Psicologia em Estudo, Maringá, v. 15, n. 1, p. 17-26, jan./mar. 2010. Doi: http://dx.doi.org/10.1590/S1413-73722010000100003. Acesso em: 9 abr. 2020.

MAGALHÃES, Vinicius Pinheiro de. Marxismo e subjetividade em Eduardo Vasconcelos: uma revisão crítica do pluralismo teórico do serviço social brasileiro. $\mathbf{O}$ Social em Questão, ano 23, n. 47, p. 245-270, 2020.

MAIOR, Nivea Maria Santos Souto et al. Direitos humanos e Serviço Social: demandas e desafios contemporâneos. Temporalis, Brasília (DF), n. 36, p. 127-138, 2018. Doi: http://dx.doi.org/10.22422/temporalis.2018v18n36p127-138. Acesso em: o9 abr. 2020.

MARX, Karl. Sobre a questão judaica. São Paulo: Boitempo, 2010.

MOYSÉS, Maria Aparecida Affonso; COLLARES, Cecília Azevedo Lima. Patologização da vida de crianças e adolescentes em tempos sombrios. In: AMARANTE, Paulo; PITTA, Ana Maria Fernandes; OLIVEIRA, Walter Ferreira de (orgs.). Patologização e medicalização da vida: epistemologia e política. São Paulo: Zagodoni, 2018, p. 151-162.

OLIVEIRA, Walter Ferreira de. Medicalização da vida: reflexões sobre sua produção cultural. In: AMARANTE, Paulo; PITTA, Ana Maria Fernandes; OLIVEIRA, Walter Ferreira de (orgs.). Patologização e medicalização da vida: epistemologia e política. São Paulo: Zagodoni, 2018. p.11-16.

VASCONCELOS, Eduardo Mourão. Da hiperpsicologização normatizadora ao recalcamento da subjetividade: notas históricas sobre Serviço Social, subjetividade e saúde mental no Brasil e no Rio de Janeiro. In: VASCONCELOS, Eduardo Mourão (org.). Saúde mental e Serviço Social: o desafio da subjetividade e da interdisciplinaridade. 5. ed. São Paulo: Cortez, 2010. p. 181-214.

VINAGRE, Marlise. Ética, direitos humanos e projeto profissional emancipatório. In: FORTI, Valeria; GUERRA, Yolanda (orgs.). Ética e direitos: ensaios críticos. 3. ed. Rio de Janeiro: Lumen Juris, 2011, p. 107-122.

WHITAKER, Robert. Anatomia de uma epidemia: Pílulas mágicas, drogas psiquiátricas e o aumento assombroso da doença mental. Rio de Janeiro: Fiocruz, 2017. 
Vinícius Pinheiro de MAGALHÃES Trabalhou na redação do artigo e na concepção e delineamento do manuscrito.

Mestre em Serviço Social pelo Programa de Pós-graduação da Universidade Federal de Sergipe (PROSS). Graduado em Serviço Social pelo Centro de Artes Humanidades e Letras (CAHL) da Universidade Federal do Recôncavo da Bahia (UFRB). Coordenador do Centro de Referência Especializado de Assistência Social (CREAS) do Município de Cruz das Almas (BA). Membro do Grupo de Estudos e Pesquisas em Fundamentos, Formação em Serviço Social e Políticas Sociais (GEPSSO) da Universidade Federal de Sergipe (UFS).

Vera Núbia SANTOS Trabalhou no delineamento do artigo e em sua revisão crítica.

Possui graduação em Serviço Social pela Universidade Federal de Sergipe (1992), mestrado (2001) e doutorado (2009) em Serviço Social pela Pontifícia Universidade Católica de São Paulo. É professora do quadro efetivo da Universidade Federal de Sergipe, em nível de graduação e pós-graduação e avaliadora ad hoc do Instituto Nacional de Estudos e Pesquisas Educacionais. Desenvolve pesquisas sobre condições de trabalho de assistentes sociais, Arte e Serviço Social, Pesquisa em Serviço Social e Política Social. 